Research Article

\title{
Study on the Vibration Effect of Short Footage Blasting Load on Surrounding Rock-Support Structure of Tunnel
}

\author{
Chunquan Dai $\mathbb{D}$, Hongtao Sui, and Chao Ma \\ School of Civil Engineering and Architecture, Shandong University of Science and Technology, Qingdao, Shandong 266590, China \\ Correspondence should be addressed to Chunquan Dai; dcqwin@sdust.edu.cn
}

Received 30 June 2020; Revised 17 August 2020; Accepted 27 August 2020; Published 7 September 2020

Academic Editor: Xianjie Hao

Copyright ( 92020 Chunquan Dai et al. This is an open access article distributed under the Creative Commons Attribution License, which permits unrestricted use, distribution, and reproduction in any medium, provided the original work is properly cited.

In the excavation process of a drilling and blasting tunnel, it takes multiple blasting excavations to form, so it is inevitable to produce multiple blasting impact loads, which will cause certain vibration damage to the surrounding rock-support structure. To solve this problem, based on the attenuation formula of blasting vibration wave and considering the cumulative effect of short footage blasting load, the radial displacement formula of surrounding rock particles is derived, and the analytical solution of vibration velocity field is obtained by using the method of separating variables. Then, taking Cuobuling station of Qingdao Metro as the engineering background, the finite element software is used to simulate the tunnel excavation process under the action of short footage multiple blasting. The vibration damage impact of multiple blasting loads on the surrounding rock-supporting structure is analyzed from the accumulated displacement value and vibration velocity cumulative value of the excavation tunnel. The results show that the damage accumulation effect is produced in the surrounding rock of each section during the blasting construction, among which the accumulation is the largest at the arch bottom. With the increase of blasting times, the damage of the surrounding rock is still accumulating gradually. Compared with the first blasting, the peak value of vibration velocity of the second blasting increased by $114 \%$, and with the increase of blasting times, the variation trend of maximum vibration velocity of the measuring point showed an upward trend, but the subsequent vibration acceleration decreased. Under the condition of grade $\mathrm{V}$ surrounding rock, when the thickness of the concrete spray layer is $350 \mathrm{~mm}$, the maximum displacement cumulative value of each measuring point in profile $1-1$ is reduced by about $50.4 \%$ compared with that without support. According to the displacement nephogram of the concrete spray layer, the displacement of the concrete spray layer accumulates after three times of blasting, which affects the stability of the supporting structure. Finally, an example analysis is carried out and compared with the analytical model results to verify the accuracy of the mechanical model.

\section{Introduction}

Due to the advantages of high excavation efficiency, strong adaptability to surrounding rock, low economic cost, and relatively mature technology, the drilling-blasting method is still the main construction method in the selection of mountain tunnel construction scheme [1-5]. The blasting vibration produced by the drilling-blasting method will damage the surrounding rock and supporting structure of the tunnel, especially in the process of short footage blasting construction, in which the surrounding rock and supporting structure will be damaged by blasting vibration for many times, and the stability of the surrounding rock and support structure in the construction process plays a decisive role in the safety of drilling and blasting construction. Therefore, ensuring the stability of the surrounding rock and supporting structure is the key to the design and construction of short footage blasting tunnels.

Throughout the past research, domestic and foreign scholars have conducted a series of studies on the vibration effect of surrounding rock-supporting structure under blasting impact load. In terms of numerical simulation, Shin et al. [6-8] determined the safety criterion of blasting according to the maximum tensile strength theory and the analysis results of LS-DYNA software and obtained the time sequence characteristics, vibration velocity, and effective stress of tunnel lining and surrounding rock at different positions; Saiang [9] used numerical simulation to study the 
damage behavior of surrounding rock caused by blasting vibration and found that the damage around the tunnel is mostly confined to the shallow buried damage area; Benselama et al. [10] found that the longitudinal spatial distribution of shock wave propagation in the tunnel can be divided into two regions: (1) the near explosion area near the explosion source presents the air-free field overpressure attenuation mode and (2) the far field far away from the explosion source can be regarded as one-dimensional overpressure attenuation mode; Tiwari et al. [11] established a three-dimensional nonlinear finite element analysis model of the internal explosion of reinforced concrete lining tunnels to study the dynamic response of weathered rock tunnels under blasting loads. In terms of field test, Gao et al. [12] comprehensively studied the influence of initiation position on the explosion vibration field and its action mechanism through theoretical calculation and experimental methods; Chen et al. [13-16] used the similarity ratio theory to carry out model experiments and explored the influence of blasting parameter changes on the vibration effect by comparing the field measured data; Otto et al. $[17,18]$ further revealed the relationship between blasting construction and rock crack development by comparing the laws between elastic wave velocities. It can be seen that most studies are often based on the theory of single blasting, and drilling and blasting construction is not completed by one blasting, but requires multiple blasting. It is inevitable that the cumulative effect of blasting load on the surrounding rock and initial support structure within a certain range from the blasting face will be produced. This cumulative effect is especially obvious in short footage blasting excavation. However, there is little systematic research on the influence of short footage blasting load on the surrounding rock and support structure vibration. In addition, under the influence of a short footage blasting seismic wave, the vibration velocity field of the tunnel surrounding rock has not been solved, and the influence of blasting vibration on the underground supporting structure has not been discussed. The dynamic response of the surrounding rock and support structure under short footage blasting load needs further study.

Therefore, this study takes Qingdao Metro blasting excavation as an example; considering the cumulative effect of short footage blasting load, the dynamic response analytical model of surrounding rock under blasting vibration is derived from the two dynamic response parameters of vibration peak value and displacement peak value. Based on the analytical model, the vibration damage of the surrounding rock and initial support structure under short footage blasting load is numerically simulated by using finite element software. The influence law of short footage blasting load on the vibration of the surrounding rock and supporting structure of the tunnel is analyzed, and the results are compared with the analytical model to verify the accuracy of the dynamic response analytical model. Related research can provide theoretical basis and technical guidance for the stability of the subway tunnel surrounding rocksupporting structure under multiple blasting loads with short footage.

\section{Dynamic Response under Blasting Vibration}

2.1. Analytical Model of Seismic Wave Propagation Velocity. The tunnel shape is simplified as a circle. The blasting load is simplified as a vibration source that decays with a negative exponential power with distance, as shown in Figure 1. The load form is $p=A_{0} \exp (-\alpha t)$, where $p$ is the blasting load, $\mathrm{Pa} ; A_{0}$ is the blasting load amplitude, $\mathrm{Pa} \alpha \alpha$ is the attenuation index; and $t$ is the time, s.

According to the relationship between stress and displacement in axisymmetric cylindrical coordinates [19, 20], there is

$$
\sigma_{r r}=\frac{E}{1+\mu}\left(\frac{\mu}{1-2 \mu} \theta+\frac{\partial U_{r}}{\partial r}\right)
$$

where

$$
\theta=\varepsilon_{r}+\varepsilon_{\phi}+\varepsilon_{z}=\frac{\partial U_{r}}{\partial r}+\frac{U_{r}}{r}+\frac{\partial W}{\partial z}
$$

According to the relationship between displacement and velocity in cylindrical coordinates, the radial velocity and axial velocity are obtained, respectively.

$$
\begin{aligned}
V_{r}= & -m c_{p} A_{1}\left[\frac{1}{2} r^{-(3 / 2)} \cos \left(\sqrt{n^{2}-m^{2} r}-\frac{\pi}{4}\right)\right. \\
& \left.+r^{-(1 / 2)} \sqrt{n^{2}-m^{2}} \sin \left(\sqrt{n^{2}-m^{2} r}-\frac{\pi}{4}\right)\right] e^{-n z} e^{-m c_{p} t},
\end{aligned}
$$

$V_{\theta}=0$,

$$
V_{r}=-m c_{p} A_{2} r^{-(1 / 2)} \cos \left(\sqrt{n^{2}-m^{2} r}-\frac{\pi}{4}\right) e^{-n z} e^{-m c_{p} t}
$$

Thus, the expression of velocity field of the surrounding rock with axial distance, radial distance, and time under short footage explosion load is determined completely.

\subsection{The Analytical Solution of Radial Displacement Based on} Cumulative Effect of Particle Velocity. The research on the theoretical model of rock blasting has experienced the development process from elastic theory to fracture mechanics theory to damage mechanics theory $[21,22]$. Based on the indepth research, the theoretical model of damage mechanics has become one of the main research directions. Based on isobaric conditions, this paper establishes a mechanical model of the surrounding rock with an excavation radius of $R_{0}$ without a supporting structure by analyzing the displacement of the surrounding rock mass and blasting vibration [23-25], as shown in Figure 2.

Based on the attenuation law of blasting vibration wave and surrounding rock blasting mechanism [26], the expressions of $\sigma_{r}$ (radial stress) and $\sigma_{\theta}$ (tangential stress) of any 


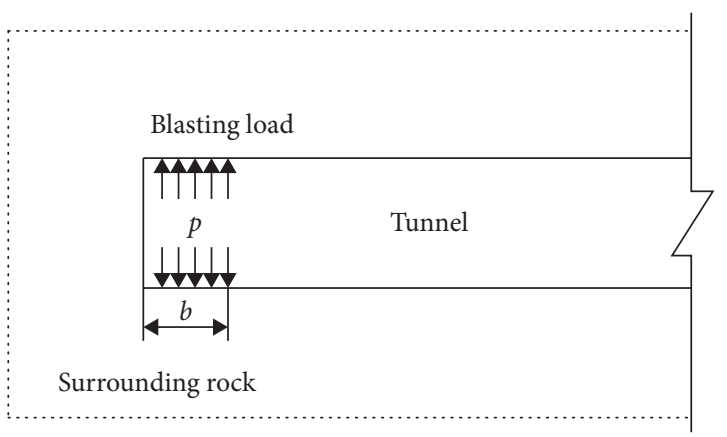

FIGURE 1: Calculation model of seismic wave propagation.

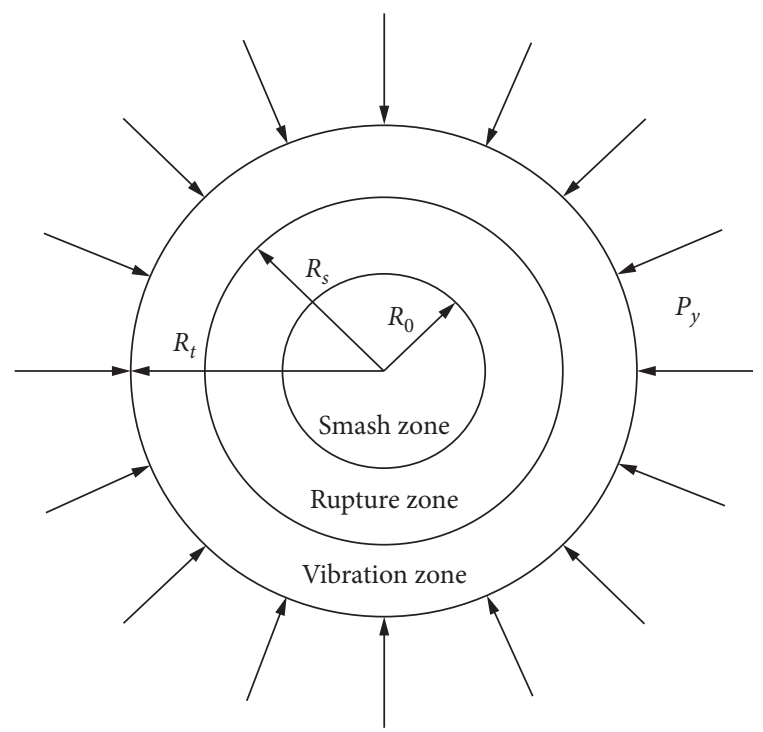

FIGURE 2: Mechanical model of the surrounding rock.

particle $O$ outside the smash zone under the condition of unsupported structure are derived:

(i) Radial stress:

$$
\sigma_{r}=\frac{R_{0}^{2}\left(R_{0}^{2}-r^{2}\right)}{r^{2}} P_{y}
$$

(ii) Tangential stress:

$$
\sigma_{\theta}=\frac{R_{0}^{2}\left(R_{0}^{2}+r^{2}\right)}{r^{2}} P_{y},
$$

where $R_{0}$ is the radius of the smash area and $r$ is the distance between point $O$ and center.

Organizing the above formula, we get

$$
\begin{gathered}
\sigma_{r}=\frac{\left(\left(n^{2} u_{0}^{2} r_{0}^{2}\right) /\left(c_{p}-m\right)^{2}\right)\left[\left(\left(n^{2} u_{0}^{2} r_{0}^{2}\right) /\left(c_{p}-m\right)^{2}\right)-r^{2}\right]}{r^{2}} p_{y}, \\
\sigma_{\theta}=\frac{\left(\left(n^{2} u_{0}^{2} r_{0}^{2}\right) /\left(c_{p}-m\right)^{2}\right)\left[\left(\left(n^{2} u_{0}^{2} r_{0}^{2}\right) /\left(c_{p}-m\right)^{2}\right)+r^{2}\right]}{r^{2}} p_{y},
\end{gathered}
$$

where $r_{0}$ is the blast hole radius and $u_{0}$ is the initial velocity of rock particles. According to the relationship between wave velocity $V_{c}$ and detonation velocity $V_{e}$, we can get

$$
u_{0}=\frac{1}{2 n \rho_{e}}\left[\sqrt{\left(\rho_{0} V_{c} V_{e}+\rho_{e} m\right)^{2}+2 n \rho_{e} \rho_{0} V_{c}^{2}}-\left(\rho_{0} V_{c} V_{e}-\rho_{e} m\right)\right] \text {, }
$$

where $\rho_{0}$ is the initial density of the rock and $\rho_{e}$ is the explosive density.

The elastic modulus and Poisson's ratio of the surrounding rock are, respectively, expressed by $E_{0}$ and $\mu_{0}$, and the radial displacement expression of particle $O$ is obtained according to the elastic mechanics model [27]:

$$
D=\frac{\left(1+\mu_{0}\right) R_{0}}{E_{0}\left(c_{p}-m\right)} \times \frac{p_{y} n^{2} u_{0}^{2} r_{0}^{2}\left[\left(1-2 \mu_{0}\right) r^{2}+\left(\left(n^{2} u_{0}^{2} r_{0}^{2}\right) /\left(c_{p}-m\right)^{2}\right)\right]}{r^{2}\left(c_{p}-m\right)^{2}} p_{y} .
$$

Upon further simplification,

$$
D=\frac{\left(1+\mu_{0}\right) R_{0}}{E_{0}} \times \frac{p_{y} R_{0}^{2}\left[\left(1-2 \mu_{0}\right) r^{2}+R_{0}^{2}\right]}{r^{2}} p_{y} .
$$

The radial displacement obtained by the above formula is based on the single blasting theory. Since the cumulative effect of short footage blasting load should be considered in this paper, the radial displacement formula of particle $O$ is further improved:

$$
D=\sum_{i=1}^{n} \frac{\left(1+\mu_{0}\right) R_{0}}{E_{0}} \times \frac{p_{y} R_{0}^{2}\left[\left(1-2 \mu_{0}\right) r^{2}+R_{0}^{2}\right]}{r^{2}} p_{y} \alpha_{i},
$$

where $n$ denotes the blasting time and $\alpha_{i}$ denotes the influence coefficient of short footage blasting.

$$
\alpha_{i}=m\left[\frac{\ln \left(L+l_{i}\right)}{3 l_{i}}\right]^{n},
$$

where the influence coefficient of short footage blasting is related to the distance $l$ from the blasting source, the excavation footage $L(L \leq 1)$, and the rock properties.

By introducing equation (13) into equation (12), it can be obtained that

$$
D=\sum_{i=1}^{n} \frac{\left(1+\mu_{0}\right) R_{0}}{E_{0}} \times \frac{p_{y} R_{0}^{2}\left[\left(1-2 \mu_{0}\right) r^{2}+R_{0}^{2}\right]}{r^{2}} m\left[\frac{\ln \left(L+l_{i}\right)}{3 l_{i}}\right]^{n} p_{y} .
$$




\section{Numerical Simulation of Cumulative Damage of Unsupported Rock Mass under Short Footage Blasting Load}

3.1. Project Overview. The surrounding rock of tunnel at Cuobuling Station of Qingdao Metro Line 4 is grade V to VI, with poor stability of the surrounding rock and abundant groundwater [28]. In this project, the short footage blasting method is adopted for the excavation of the main body of the tunnel, with $1 \mathrm{~m}$ as the excavation footage. After the completion of tunnel excavation, C25 concrete is initially sprayed with a thickness of $350 \mathrm{~mm}$. Anchor rods of $L=3.5 \mathrm{~m}$ are set on the side walls, and the vertical and horizontal spacing is at $1.0 * 1.0 \mathrm{~m}$, arranged in a plum blossom shape. The buried depth of the vault is $12 \mathrm{~m}$, and the span is $8 \mathrm{~m}$.

In the process of short footage blasting, the surrounding rock and initial support structure of tunnel will inevitably be affected by blasting vibration. In order to analyze the influence of short footage blasting on the surrounding rock and supporting structure of tunnel, the numerical simulation software MIDAS/GTS NX is used to study the stability of the surrounding rock and initial support structure under the influence of short footage blasting vibration, so as to guide and improve the tunnel construction scheme and provide theoretical support for construction safety.

\subsection{Model Overview}

3.2.1. Establishment of $3 \mathrm{D}$ Model. In the simulation process, in order to facilitate the calculation and reduce the amount of calculation, the model size is set as $80 \times 60 \times 20(\mathrm{~m})$. In the simulation process, in order to facilitate the calculation and reduce the amount of calculation, the model size is set to $80 \times 60 \times 20(\mathrm{~m})$, the excavation footage is $1 \mathrm{~m}$, and the impact of the $\mathrm{V}$-class surrounding rock by the short footage blasting load is simulated. The $3 \mathrm{D}$ model is shown in Figure 3.

3.2.2. Selection of Material Parameters. In order to simplify the calculation process, the surrounding rock material is assumed to be an elastic-plastic body under ideal conditions. Based on the actual geological survey data, grade $\mathrm{V}$ surrounding rock is selected for construction analysis. The relevant basic physical and mechanical parameters of grade $\mathrm{V}$ surrounding rock are shown in Table 1, and the excavation footage is shown in Figure 4.

3.3. Analysis of Surrounding Rock Simulation Results. The peak value of vibration velocity and displacement under blasting dynamic load is an important parameter reflecting the dynamic response of the tunnel, which is often used as the basis for analyzing and judging the vibration safety of the tunnel, roadway, and cutting slope. In this numerical analysis, the representative arch bottom, arch top, left arch waist, and right arch waist of the tunnel are taken as the measuring points, and a total of 20 measuring points are selected in the whole excavation process. Taking the following four working sections as the test range, the displacement change trend of the measuring point is shown in Figure 5.

3.3.1. Displacement Analysis. The trend of displacement after blasting at the measuring point at the arch bottom of 11 profile is shown in Figure 5:

It can be seen from Figure 5 that the maximum displacement of the measuring point at the arch bottom after the first blasting is $25.642 \times 10^{-3} \mathrm{~m}$. With the increase of blasting times, the maximum displacement of the measuring point shows an upward trend. The peak values of the last four blasts are, respectively, $40.745 \times 10^{-3} \mathrm{~m}, \quad 40.735 \times 10^{-3} \mathrm{~m}, 40.957 \times 10^{-3} \mathrm{~m}$, and $46.642 \times 10^{-3} \mathrm{~m}$, indicating that the displacement damage gradually accumulates with the increase of blasting times. However, the growth rate of the overall displacement shows a rapid decline trend, which shows that, with the increase of distance, the impact of blasting load on surrounding rock is becoming smaller and smaller.

The peak displacement at the measured section is shown in Tables 2-4. Due to the space limitation, only typical sections are listed.

Through the analysis of the data in Tables $2-4$, it can be concluded that

(1) The results show that the cumulative effect occurs in the surrounding rock of each section during the blasting construction, and the peak value of the displacement at the bottom of the arch fluctuates the most, and the maximum displacement accumulation value of the arch top and the left and right arches is equivalent.

(2) It can be seen from Table 2 that the displacement value of each measuring point in section 1-1 of grade $\mathrm{V}$ surrounding rock increases by $15.1 \mathrm{~mm} \sim 17.2 \mathrm{~mm}$ after the second and third blasting, and the maximum displacement value after the fourth and fifth blasting is only increased by about $2 \mathrm{~mm}$ compared with the third blasting. Therefore, for section 1-1 (i.e., the surrounding rock of the tunnel after the first blasting), with the increase of the distance from the excavation face, the impact of blasting load on it is also gradually reduced, and the influence of the second blasting is greater in the fifth blasting.

(3) It can be seen from Table 3 that the displacement value of the first three blastings of section 3-3 increases slowly, and the maximum value appears at the arch bottom. After the fourth and fifth blasting, the displacement reached $22.842 \times 10^{-3} \mathrm{~m}$ and $46.642 \times 10^{-3} \mathrm{~m}$, with the growth rate of $81 \%$ and $104 \%$. Compared with the first three blastings, the peak displacement increased faster. The maximum displacement peak of 3-3 profile is still at the arch bottom, reaching $46.642 \times 10^{-3} \mathrm{~m}$.

(4) It can be seen from Table 4 that the displacement value generated by the first blasting of section 5-5 


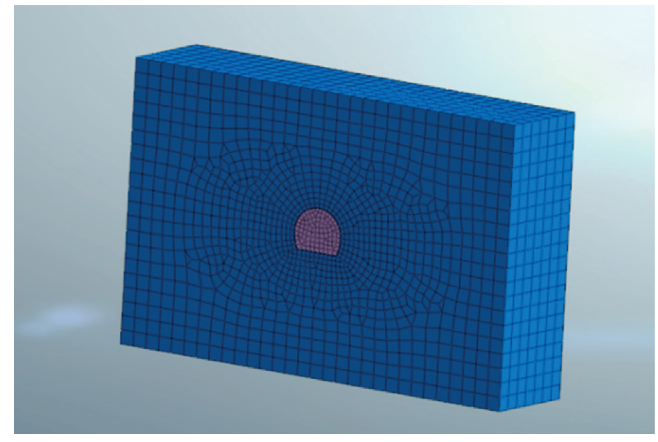

(a)

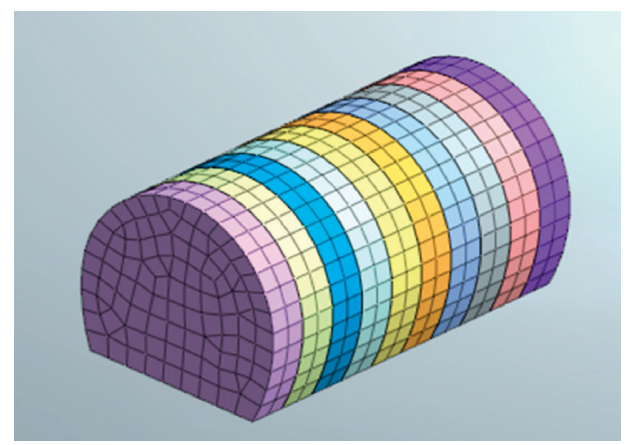

(b)

Figure 3: 3D model diagram. (a) 3D model of the surrounding rock and tunnel. (b) $1 \mathrm{~m}$ excavation footage.

TABLE 1: Physical and mechanical parameters of the surrounding rock.

\begin{tabular}{lcccc}
\hline $\begin{array}{l}\text { Grade of the surrounding } \\
\text { rock }\end{array}$ & $\begin{array}{c}\text { Elastic modulus } E \\
\left(\mathrm{KN} / \mathrm{m}^{2}\right)\end{array}$ & $\begin{array}{c}\text { Poisson's ratio } \\
v\end{array}$ & $\begin{array}{c}\text { The angle of internal } \\
\text { friction } \phi\end{array}$ & $\begin{array}{c}\text { Volumetric weight } \rho \\
\left(\mathrm{KN} / \mathrm{m}^{2}\right)\end{array}$ \\
\hline $\mathrm{V}$ & $1.3 \times 10^{6}$ & 0.40 & 20 & $\begin{array}{c}\text { Cohesiveforces } c \\
\left(\mathrm{KN} / \mathrm{m}^{2}\right)\end{array}$ \\
\hline
\end{tabular}

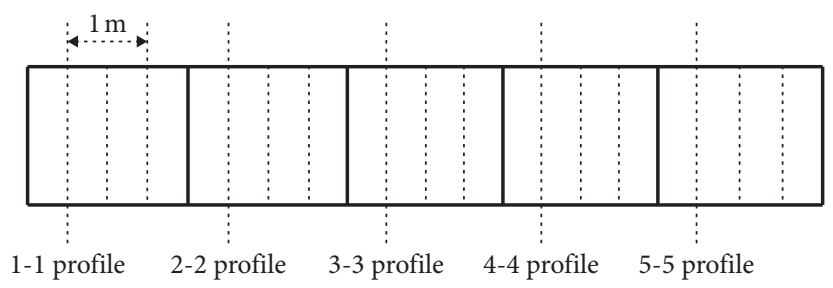

FIGURE 4: Schematic diagram of $1 \mathrm{~m}$ excavation footage.

reaches $8.536 \times 10^{-3} \mathrm{~m}$, and then, with the increase of blasting times, the acceleration of displacement peak value accelerates. After the fourth and fifth blasting, the maximum displacement value increased significantly, with the growth rate of $62.7 \%$ and $62.1 \%$, indicating that the damage mutation of surrounding rock after the fourth blasting is the largest. The maximum displacement peak of 5-5 profile is still at the arch bottom.

The maximum cumulative displacement values of the four measuring points from 1-1 section to 5-5 section after 5 times of blasting are plotted as a broken line diagram, as shown in Figure 6.

It can be seen from Figure 6 that, among sections 1-1 55 , the cumulative displacement of each measuring point at section 3-3 is the largest, which is $46.64 \mathrm{~mm}$. At section 3-3, the relative displacement of the arch bottom and arch top is $92.19 \mathrm{~mm}$, and the relative displacement of the left and right arch waist is $91.03 \mathrm{~mm}$. Taking the cumulative displacement value as a reference, considering the actual construction safety problems, the excavation footage of $1 \mathrm{~m}$ is too large for grade $\mathrm{V}$ surrounding rock. Therefore, the excavation footage less than $1 \mathrm{~m}$ should be adopted in the process of tunnel excavation by cyclic blasting, and the time from blasting excavation to completion of initial support closure should be shortened. This is consistent with the engineering measures of Qingdao Metro Line 4, which proves the effectiveness and accuracy of the numerical simulation.

3.3.2. Vibration Velocity Analysis. The variation of vibration velocity at the arch bottom of section 1-1 is shown in Figure 7.

According to the analysis of the above figure, the maximum vibration velocity of the measuring point at the arch bottom after the first blasting is $13.034 \times 10^{-2} \mathrm{~m} / \mathrm{sec}$. With the increase of blasting times, the variation trend of the maximum vibration velocity of the measuring point presents an upward trend. But after the second blasting, the change tends to be gentle. With the increase of blasting times, the damage gradually accumulates.

The peak value of vibration velocity at each section is shown in Tables 5-7.

Through the analysis of the data in Tables 5-7, it can be concluded that

(1) The damage accumulation effect is produced in all sections of the surrounding rock during the blasting construction, among which the accumulation is still the largest at the bottom of the arch, and the peak value of vibration velocity at other measuring points changes relatively little, but the damage of surrounding rock is still accumulating gradually. 


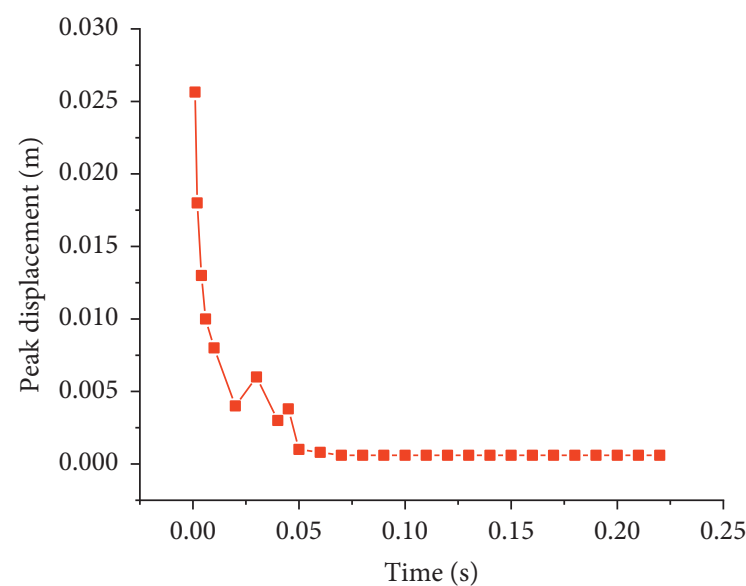

(a)

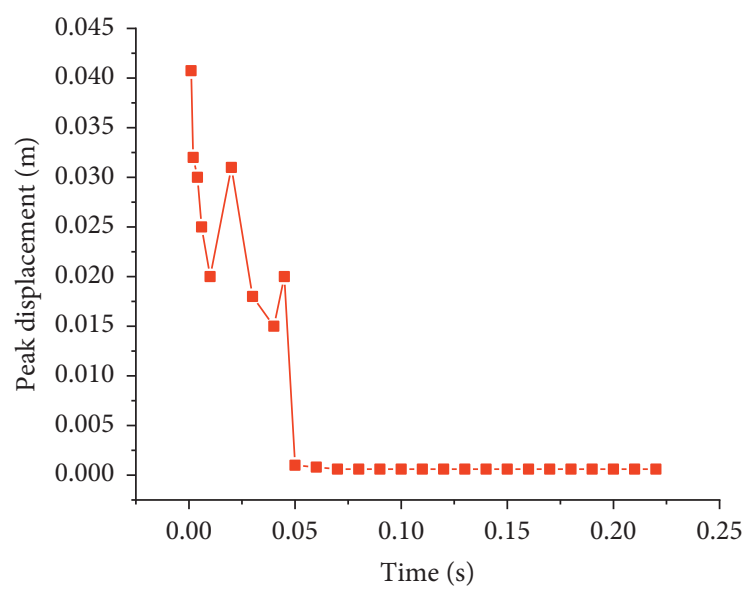

(c)

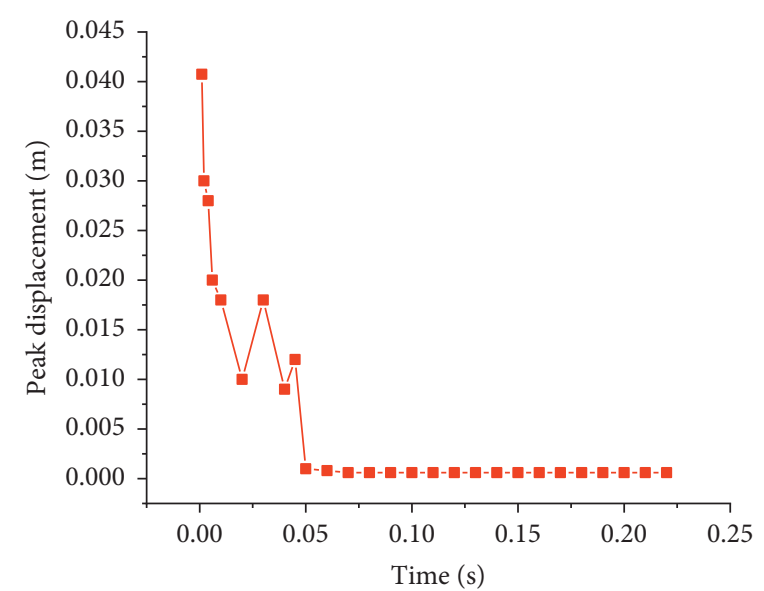

(b)

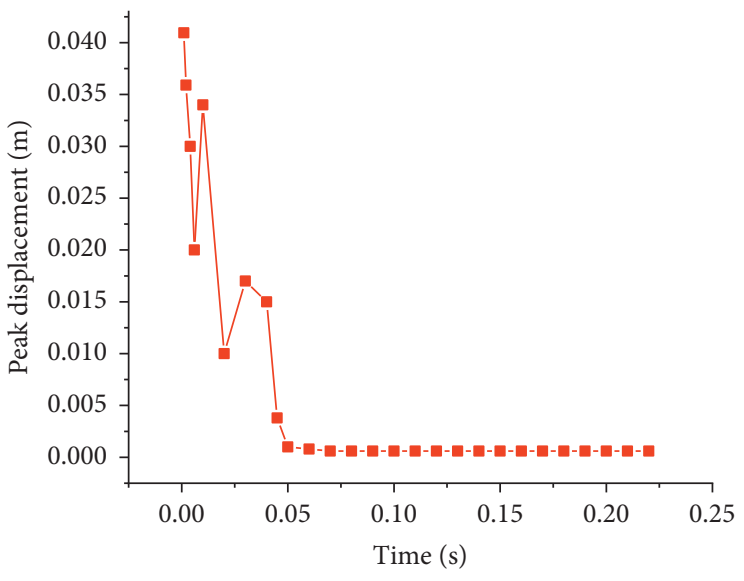

(d)

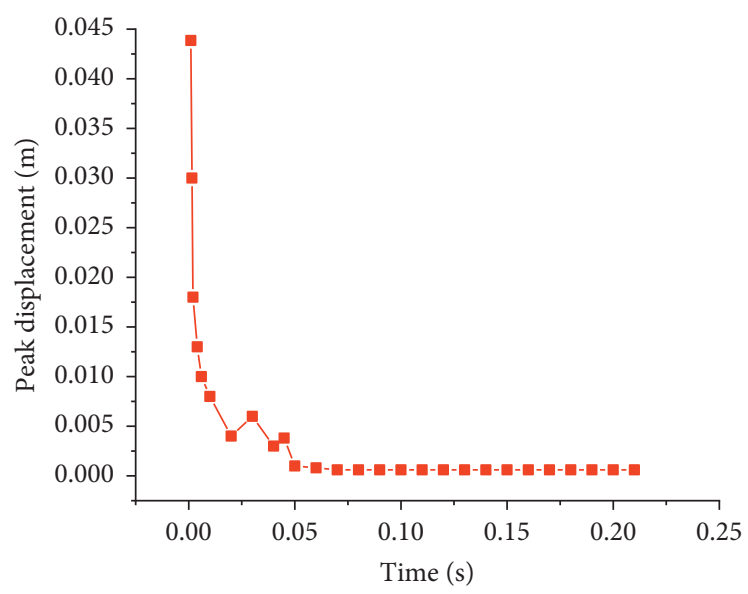

(e)

Figure 5: Displacement change of the arch bottom measuring point at profile 1-1. (a) First blast. (b) Second blast. (c) Third blast. (d) Fourth blast. (e) Fifth blast. 
TABLe 2: Peak displacement at each measuring point of 1-1 profile (mm).

\begin{tabular}{lcccc}
\hline Blasting times & Arch bottom & Arch top & Left arch waist & Right arch waist \\
\hline 1 & 25.642 & 23.234 & 23.342 & 23.765 \\
2 & 40.745 & 40.244 & 40.534 & 40.875 \\
3 & 40.735 & 40.243 & 40.654 & 40.896 \\
4 & 40.957 & 40.355 & 40.647 & 40.978 \\
5 & 43.852 & 42.534 & 42.524 & 42.632 \\
\hline
\end{tabular}

TABle 3: Peak displacement at each measuring point of 3-3 profile (mm).

\begin{tabular}{lcccc}
\hline Blasting times & Arch bottom & Arch top & Left arch waist & Right arch waist \\
\hline 1 & 8.421 & 8.246 & 8.264 & 8.421 \\
2 & 10.354 & 9.973 & 9.634 & 9.653 \\
3 & 12.632 & 12.174 & 12.362 & 12.565 \\
4 & 22.842 & 22.352 & 22.532 & 22.532 \\
5 & 46.642 & 45.543 & 45.466 & 45.563 \\
\hline
\end{tabular}

TABLE 4: Peak displacement at each measuring point of 5-5 profile $(\mathrm{mm})$.

\begin{tabular}{lcccc}
\hline Blasting times & Arch bottom & Arch top & Left arch waist & Right arch waist \\
\hline 1 & 8.536 & 8.345 & 8.563 & 8.653 \\
2 & 11.421 & 11.652 & 11.543 & 11.452 \\
3 & 13.435 & 13.856 & 21.645 & 13.352 \\
4 & 21.865 & 20.745 & 33.752 & 21.746 \\
5 & 35.425 & 33.452 & 34.532 \\
\hline
\end{tabular}

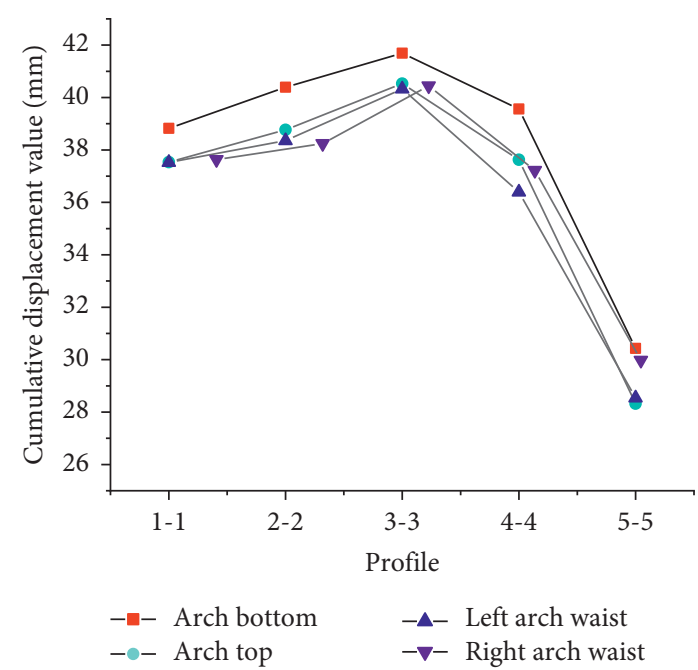

FIgURE 6: Cumulative displacement values at different measurement points in each profile.

(2) After the second blasting, the peak value of vibration velocity of the surrounding rock at 1-1 profile increases rapidly, and the vibration velocity at the bottom of the arch increases by $114 \%$ compared with the first blasting. After five times of blasting, the maximum increase of vibration velocity at 1-1 section is at the bottom of the arch, and the maximum increase rate of single blasting speed is $114 \%$.
(3) The analysis shows that the increase value of vibration velocity produced by the third blasting of section $2-2$ is $10.315 \times 10^{-2} \mathrm{~m} / \mathrm{sec}$, and the maximum increase rate of single blasting is $95 \%$. After the fourth and fifth blasting, the increase in the value of vibration velocity gradually decreases. The vibration velocity of the surrounding rock at section 3-3 increases most obviously after the fourth to fifth blasting.

(4) The first three times of vibration velocity increase rate of section 4-4 is relatively low, and the single growth rate of the fifth blasting is $74.4 \%$; The surrounding rock at section $5-5$ is most affected by the fourth blasting load, followed by the third blasting load.

The maximum cumulative value of the vibration velocity of four measuring points from 1-1 section to 5-5 section after five times of blasting is drawn as a broken line diagram, as shown in Figure 8.

It can be seen from Figure 8 that, among the five sections, the cumulative value of vibration velocity at each measuring point at section 3-3 is the largest, which indicates that, after five times of blasting, the damage degree of the surrounding rock at section 3-3 is the largest, and the vibration velocity of particle at the bottom of arch is the largest among the four measuring points.

In summary, it can be seen that the surrounding rock at each section has accumulated damage to varying degrees after being subjected to five blasting loads. According to the relationship between crack propagation and particle 

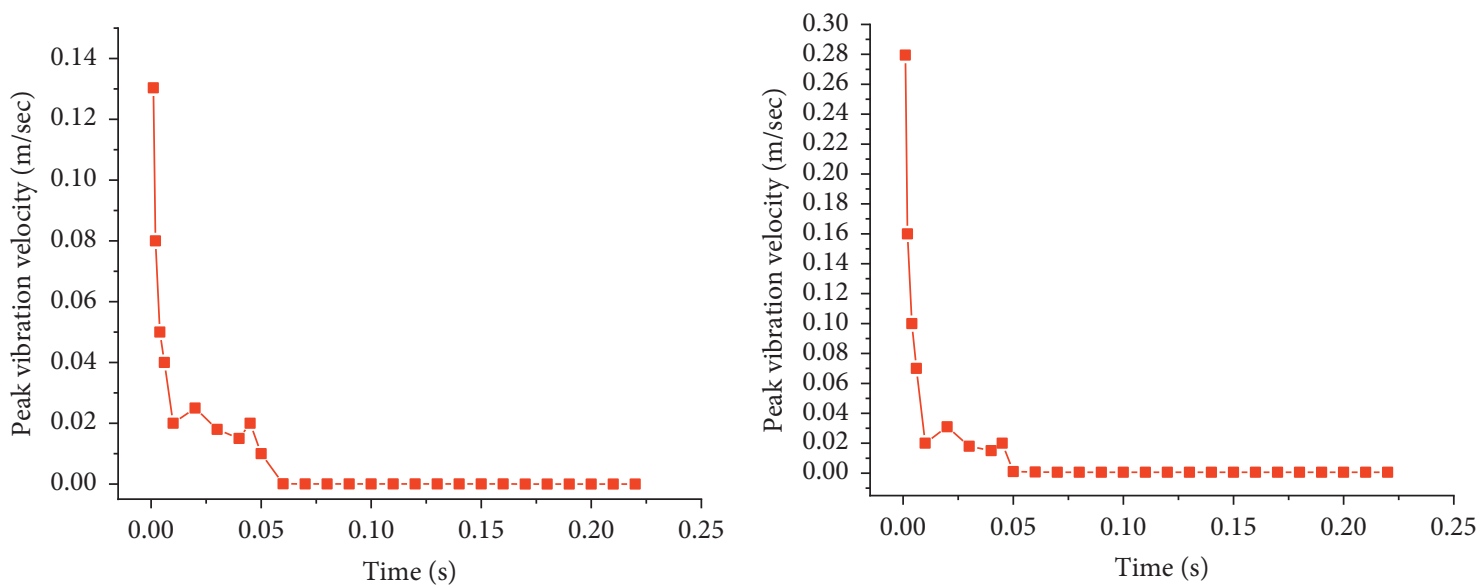

(a)

(b)

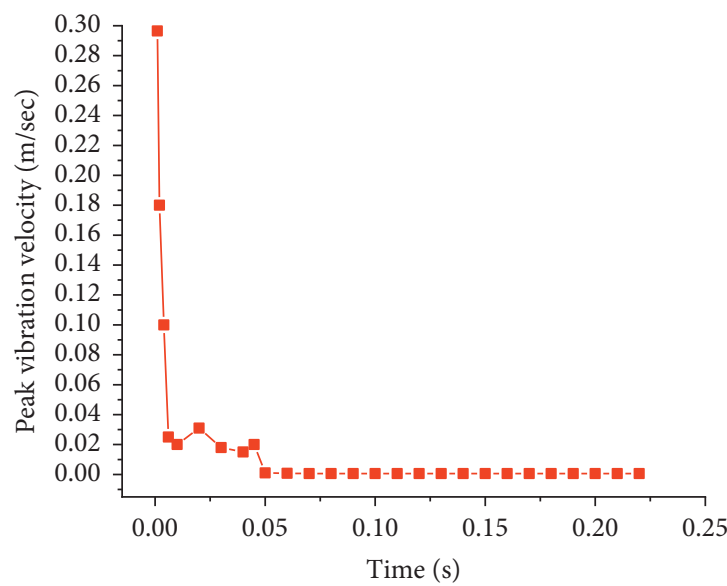

(c)

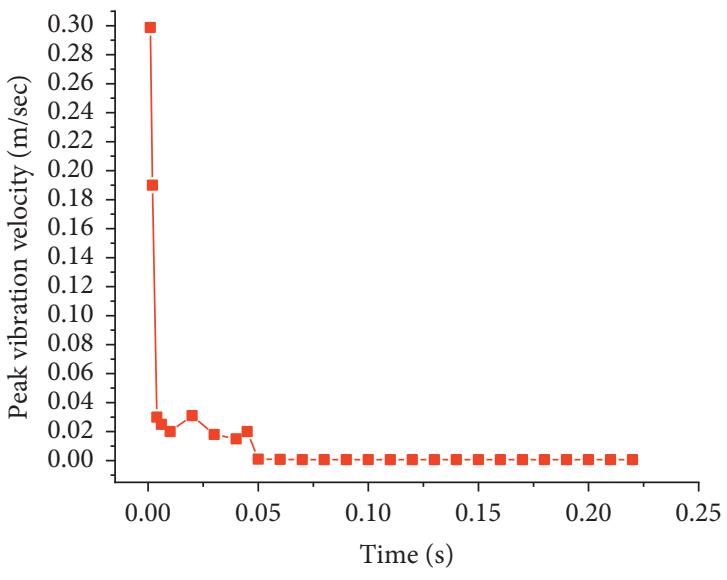

(d)

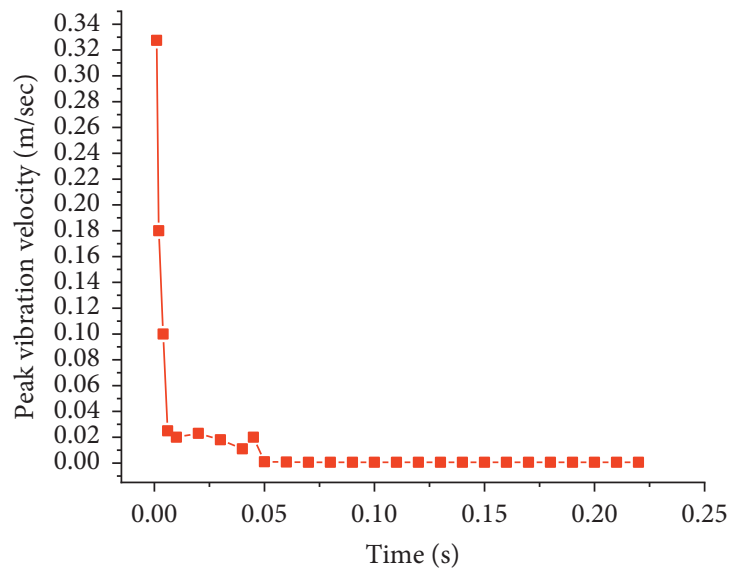

(e)

Figure 7: Vibration velocity change of the arch bottom measuring point at profile 1-1. (a) First blast. (b) Second blast. (c) Third blast. (d) Fourth blast. (e) Fifth blast. 
TABLE 5: Peak value of vibration velocity at each measuring point of profile $1-1\left(10^{-2} \mathrm{~m} / \mathrm{sec}\right)$.

\begin{tabular}{lcccc}
\hline Blasting times & Arch bottom & Arch top & Left arch waist & Right arch waist \\
\hline 1 & 13.034 & 12.422 & 12.624 & 12.524 \\
2 & 27.952 & 25.452 & 26.857 & 26.732 \\
3 & 29.654 & 28.765 & 28.354 & 28.968 \\
4 & 29.877 & 29.745 & 28.976 & 29.983 \\
5 & 32.745 & 32.657 & 31.345 & 31.987 \\
\hline
\end{tabular}

TABLE 6: Peak value of vibration velocity at each measuring point of profile $3-3\left(10^{-2} \mathrm{~m} / \mathrm{sec}\right)$.

\begin{tabular}{lcccc}
\hline Blasting times & Arch bottom & Arch top & Left arch waist & Right arch waist \\
\hline 1 & 6.360 & 4.347 & 5.348 & 4.350 \\
2 & 11.702 & 11.689 & 11.691 & 11.694 \\
3 & 14.989 & 14.965 & 14.966 & 14.955 \\
4 & 25.175 & 24.662 & 24.765 & 24.870 \\
5 & 34.352 & 33.761 & 33.891 & 34.784 \\
\hline
\end{tabular}

TABle 7: Peak value of vibration velocity at each measuring point of profile $5-5\left(10^{-2} \mathrm{~m} / \mathrm{sec}\right)$.

\begin{tabular}{lcccc}
\hline Blasting times & Arch bottom & Arch top & Left arch waist & Right arch waist \\
\hline 1 & 2.629 & 1.597 & 1.606 & 1.605 \\
2 & 4.127 & 4.084 & 8.097 & 3.123 \\
3 & 8.580 & 8.866 & 15.935 & 8.873 \\
4 & 15.735 & 15.924 & 17.087 & 15.928 \\
5 & 17.738 & 16.255 & 17.146 \\
\hline
\end{tabular}

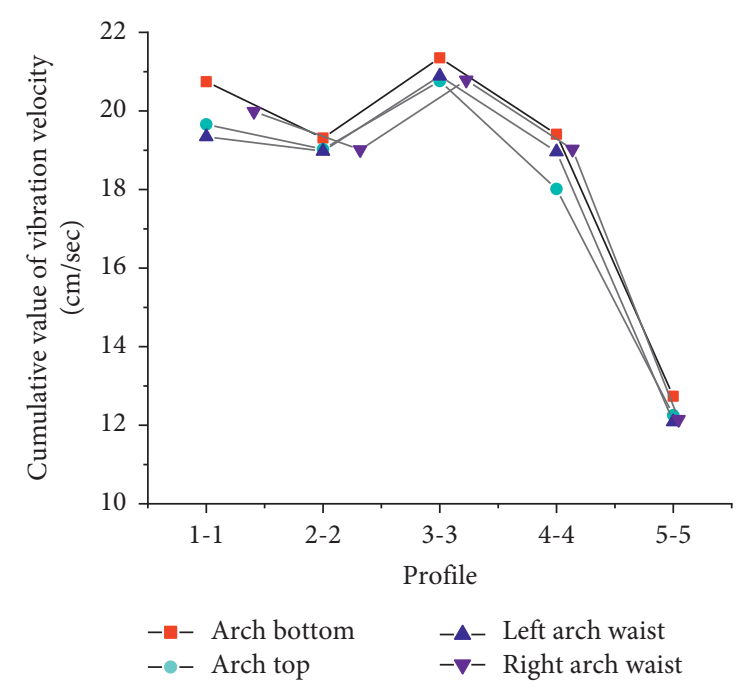

FIGURE 8: Cumulative value of vibration velocity at different measuring points of each section.

vibration velocity, when the peak value of particle vibration velocity exceeds $0.14 \mathrm{~m} / \mathrm{s}$, the surrounding rock will produce crack development and expansion, and the damage will be aggravated. Analysis of the vibration velocity of the surrounding rock shows that, after the fifth blasting construction, the peak value of the particle vibration velocity of the 3-3 section reaches $20.352 \times 10^{-2} \mathrm{~m} / \mathrm{sec}$. According to the critical value of vibration velocity, for grade $\mathrm{V}$ surrounding rock, advance support should be carried out in the actual blasting excavation process, the footage should be appropriately shortened, and the support strength of the surrounding rock at 3-3 profile and arch foot should be increased.

\section{Numerical Simulation of Cumulative Damage of Initial Support Structure under Short Footage Blasting Load}

According to the numerical simulation of short footage blasting load on the tunnel surrounding rock in Section 3.3 , it can be seen that the cumulative damage of surrounding rock will occur when the tunnel is excavated by short footage blasting. In the actual construction process, in order to ensure the safety of construction, the initial support structure should be timely applied to the excavated part. In this section, based on the previous study, shotcrete-bolt support structure is applied to the surrounding rock of the tunnel, and the reinforcement mesh is added. The numerical results of the measurement points under the condition of no support are compared and analyzed, and the influence of short footage blasting load on the initial support structure is further studied.

4.1. Selection of Support Structure Parameters and Establishment of Model. The relevant parameters of the anchor bolt and shotcrete are shown in Table 8. Single-layer $\varphi 8 @$ $200 \mathrm{~mm} \times 200 \mathrm{~mm}$ is selected for the steel fabric mesh. The establishment of tunnel shotcrete-bolt support structure model is shown in Figure 9. 
TABLE 8: Relevant parameters of initial support structure.

\begin{tabular}{lccccc}
\hline Material name & Modulus of elasticity $E\left(\mathrm{KN} / \mathrm{m}^{2}\right)$ & Poisson's ratio $v$ & Test weight $\rho\left(\mathrm{KN} / \mathrm{m}^{2}\right)$ & Model unit & Constitutive model \\
\hline Anchor & $2.3 \times 10^{8}$ & 0.3 & 80 & Implantable truss & Elasticity \\
Shotcrete & $3 \times 10^{7}$ & 0.26 & 28 & Board unit & Elasticity \\
\hline
\end{tabular}

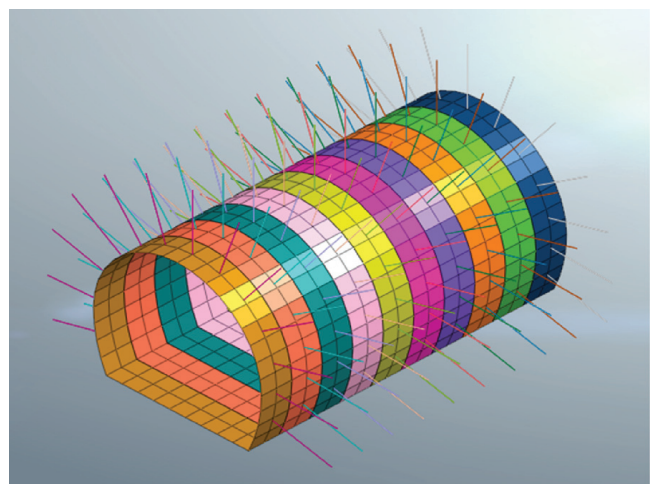

FIGURE 9: Effect drawing of tunnel shotcrete-bolt support structure.

TABLE 9: The cumulative value of displacement of each measuring point of profile 1-1 without initial support (mm).

\begin{tabular}{lcccc}
\hline Blasting times & Arch bottom & Arch top & Left arch waist & Right arch waist \\
\hline 3 & 29.654 & 28.765 & 28.354 & 28.968 \\
4 & 29.877 & 29.745 & 28.976 & 29.983 \\
5 & 32.745 & 32.657 & 31.345 & 31.987 \\
\hline
\end{tabular}

TABLE 10: The cumulative value of displacement at each measuring point of profile 1-1 when the thickness of the concrete spray layer is $350 \mathrm{~mm}(\mathrm{~mm})$.

\begin{tabular}{lcccc}
\hline Blasting times & Arch bottom & Arch top & Left arch waist & Right arch waist \\
\hline 3 & 15.743 & 15.634 & 14.577 & 15.365 \\
4 & 15.845 & 15.756 & 15.421 & 15.957 \\
5 & 16.252 & 16.221 & 16.242 & 16.243 \\
\hline
\end{tabular}

\subsection{Analysis of Simulation Results of Initial Support Structure}

\subsubsection{Analysis of Simulation Results of the Surrounding Rock} after Applying Initial Support Structure. When the thickness of the shotcrete layer is $350 \mathrm{~mm}$, the displacement time history curves of the arch bottom measuring points of profile 1-1 after the third, fourth, and fifth blasting are shown in Figure 10.

It can be seen that the change trend of the displacement of the measuring points at the arch bottom of profile 1-1 is similar to that of the blasting damage in Section 3.3. The following Tables 9 and 10. lists the displacement changes of profile 1-1 without initial support and the displacement variation values of $350 \mathrm{~mm}$ concrete spraying layer thickness.

According to the analysis in the table, the application of initial support can reduce the cumulative displacement of the surrounding rock at each measuring point.
After five times of blasting, compared with the surrounding rock without support, the displacement reduction rate is $50.4 \%$ when the thickness of the shotcrete layer is $350 \mathrm{~mm}$ (except for the first blasting). Therefore, after the completion of one-time blasting excavation, the time from blasting excavation to the completion of initial support closure is shortened to prevent excessive damage to the surrounding rock caused by cumulative effect of short footage blasting load, improve the stability of surrounding rock, and ensure the safety of blasting operation.

4.2.2. Displacement Analysis of the Concrete Spraying Layer. From the above research and analysis, it can be seen that the displacement of each measuring point in profile 1-1 after applying the initial support structure is significantly lower than that without support, which indicates that the initial support structure bears part of the surrounding rock stress 


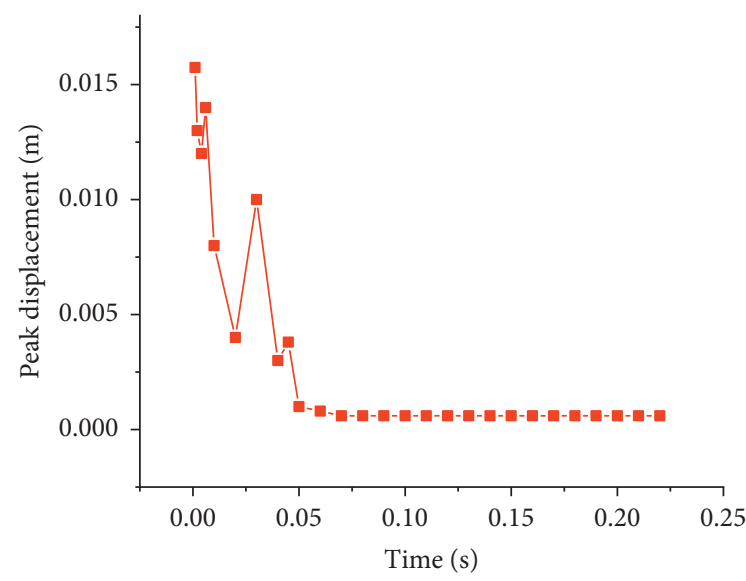

(a)

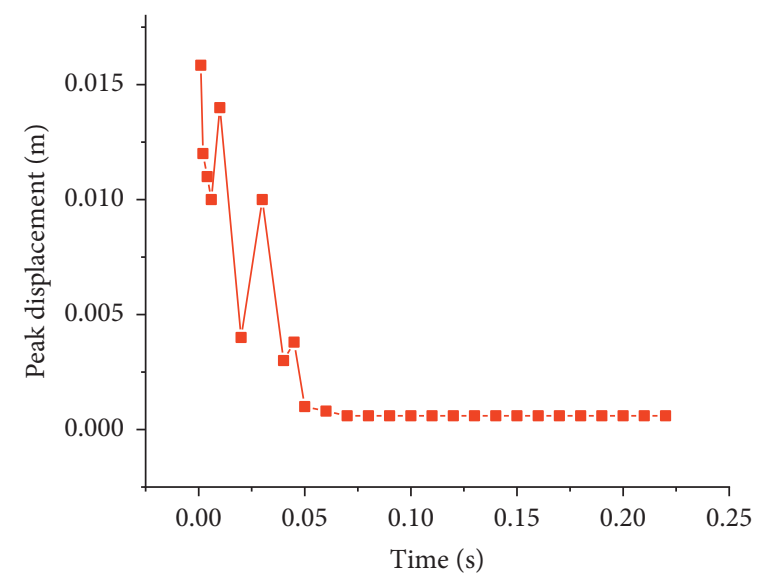

(b)

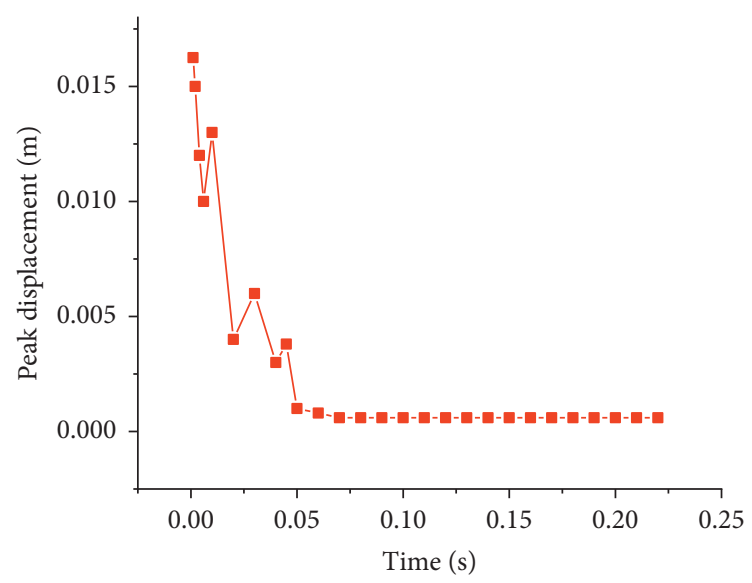

(c)

Figure 10: Displacement change of the arch bottom measuring point at 1-1 profile. (a) Third blast. (b) Fourth blast. (c) Fifth blast.

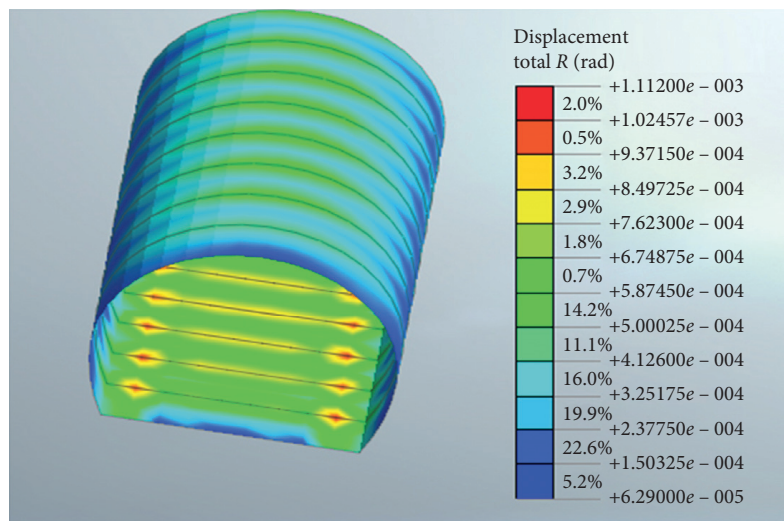

(a)

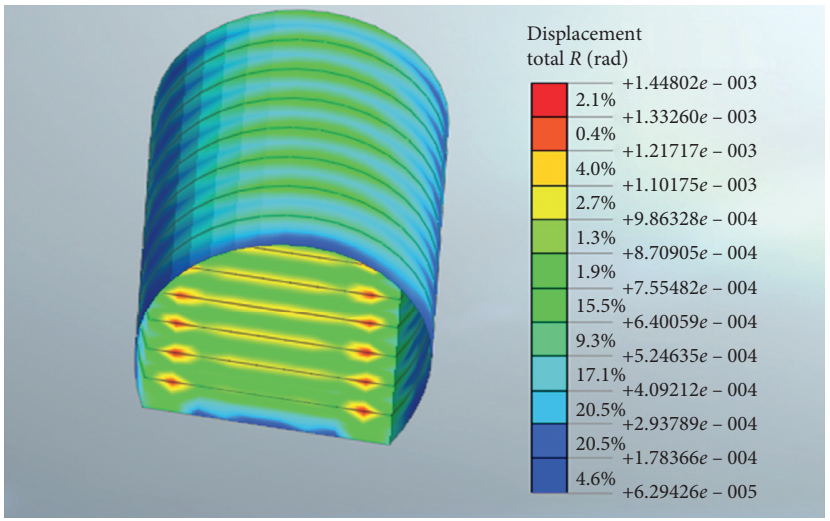

(b)

FIGURE 11: Continued. 


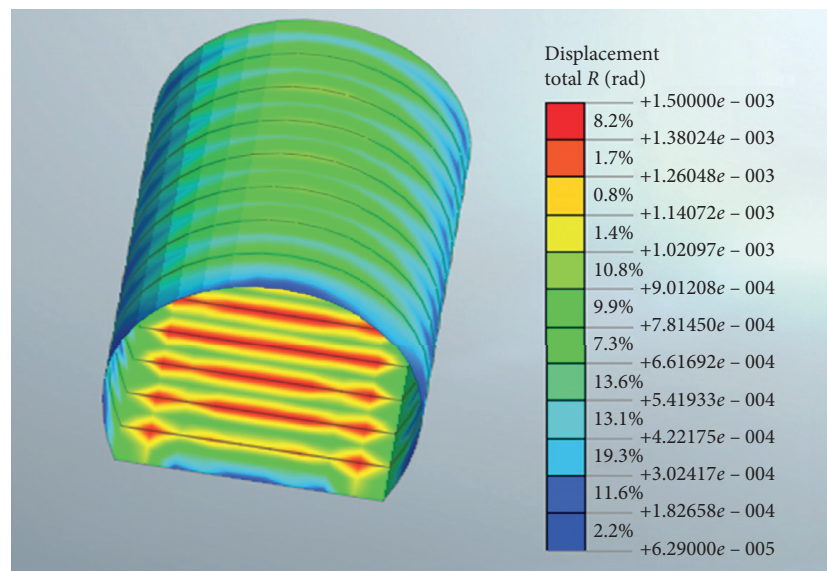

(c)

FIgURE 11: Cloud image of maximum displacement of the shotcrete layer. (a) After the third blasting. (b) After the fourth blasting. (c) After the fifth blasting.

after the short footage blasting load, thus reducing the displacement of the surrounding rock particles. This section starts from the displacement of the concrete spraying layer and further analyzes the influence of short footage blasting load on the support structure.

After three times of blasting, the maximum displacement nephogram of the concrete spraying layer is shown in Figure 11.

It can be seen from Figure 11 that the displacement of the shotcrete layer increases from $1.11 \mathrm{~mm}$ to $1.50 \mathrm{~mm}$ after three times of blasting, which indicates that the short footage cyclic blasting load causes cumulative damage to the shotcrete layer, and the maximum damage is concentrated near the arch bottom.

\section{Calculation Example}

In order to verify the accuracy of the analytical solution of the velocity field and radial displacement of the surrounding rock under short footage blasting load deduced in Section 1 of this paper, numerical simulation and field measurement are used to verify the accuracy of the analytical model. Because the excavation and support are alternate in the actual drilling and blasting excavation process, the radial displacement of the tunnel surrounding rock without support cannot be measured from the blasting excavation site, so the analytical solution of the radial displacement of the tunnel surrounding rock can only be verified by numerical simulation.

\subsection{Numerical Simulation Verification}

5.1.1. Calculation Condition. The main structure of Cuobuling station of Qingdao Metro Line 4 is excavated by the drilling and blasting method, and the surrounding smooth blasting is adopted, and the main blast hole is controlled blasting. Hand-held pneumatic drill is used to drill holes, and manual charging is used. According to the geological conditions and design requirements, the excavation footage is set as $1.0 \mathrm{~m}$.
YT28 rock drill is selected as rock drill, and the diameter of blast hole is $D=42 \mathrm{~mm}$. No. 2 emulsion explosive is used with a density of $1100 \mathrm{~kg} / \mathrm{m}^{3}$, a detonation velocity of $3200 \mathrm{~m} / \mathrm{s}$, a diameter of explosive roll of $\Phi 32 \mathrm{~mm}$, and a unit explosive consumption of $1.25 \mathrm{~kg} / \mathrm{m}^{3}$. The rock mass is slightly weathered coarse-grained granite with a density of $2.66 \mathrm{~g} / \mathrm{cm}^{3}$, an elastic modulus of $33.95 \times 103 \mathrm{MPa}$, a Poisson's ratio of 0.20 , and a load attenuation index of 4000 .

5.1.2. Analytical Solution of Velocity Field. By substituting the relevant parameters into equations (3) and (5), the velocity field caused by short footage blasting load is compared with the numerical results, as shown in Figure 12.

It can be seen from the figure that the analytical model results of particle vibration velocity are approximately consistent with the numerical simulation results, which verifies the rationality and accuracy of the analytical model. The results show that the particle vibration velocity decreases sharply with the axial distance and decreases to $7.5 \mathrm{~cm} / \mathrm{s}$ in the range of $0.5 \mathrm{~m}$ from the front face. Therefore, the impact of blasting vibration on the surrounding rock within $0.5 \mathrm{~m}$ is the most severe, and it is also the place where the support is most prone to problems.

5.1.3. Analytical Solution of Radial Displacement. The relevant parameters are brought into equation (14). The radial displacement of the surrounding rock caused by short footage blasting load is compared with the numerical simulation results, as shown in Figure 13.

It can be seen from the comparison results that the analytical model results of particle vibration velocity radial displacement agree well with the numerical simulation results, which verifies the accuracy of the mechanical model. With the increase of blasting times, the radial displacement of the tunnel surrounding rock increases gradually, which indicates that the short footage blasting load produces cumulative damage to the surrounding rock. However, with the increase of blasting 


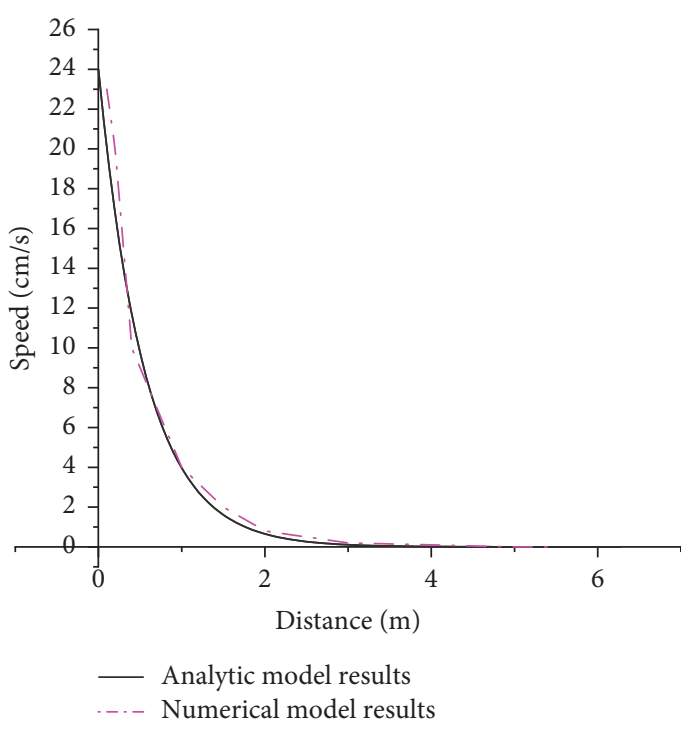

(a)

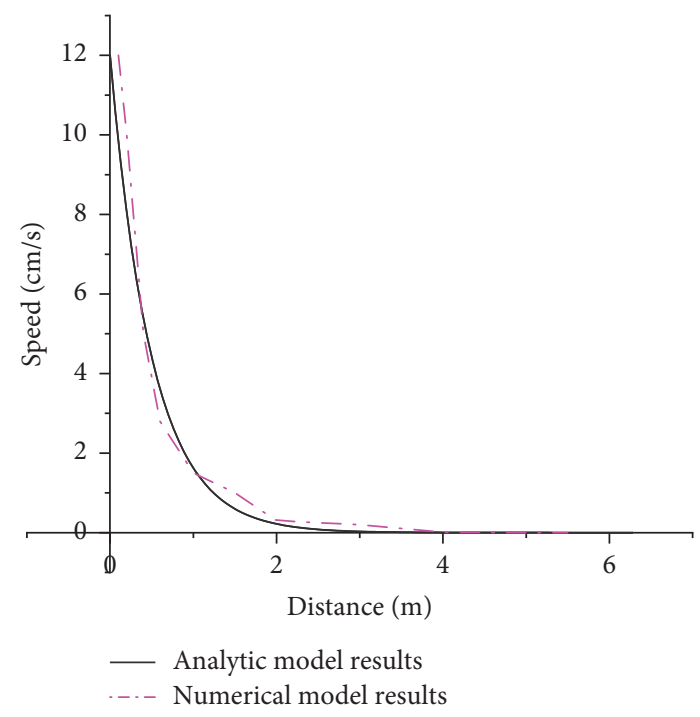

(b)

FIGURE 12: Comparison of velocity field caused by blasting load and numerical results. (a) Variation of radial speed with axial distance. (b) Variation of axial speed with axial distance.

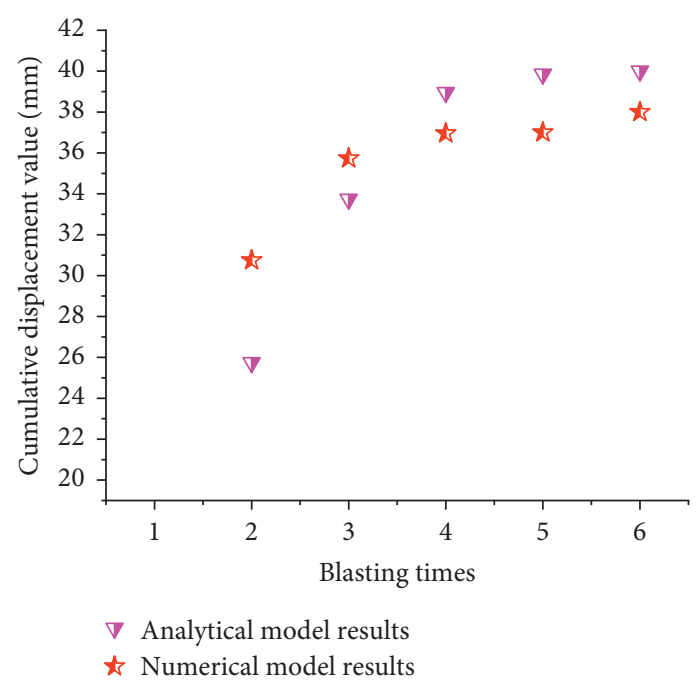

FIGURE 13: Comparison of analytical and numerical results of radial displacement.

times, the distance between the measuring point and the blasting position is getting farther and farther, and the increasing speed of displacement is obviously slowed down. In the blasting construction, it is necessary to pay special attention to the cumulative damage effect of the first three blasts on the surrounding rock, strengthen the initial support strength, and ensure the stability of the surrounding rock.

\subsection{Field Measurement Verification}

5.2.1. Calculation Condition. The stratum lithology in the project area of the Yeshanhe Tunnel is thin limestone, with a dry density of $2.68 \mathrm{~g} / \mathrm{cm}^{3}$, a uniaxial compressive strength of $75.0 \mathrm{MPa}$, a softening coefficient of 0.8 , an elastic modulus of $44.2 \mathrm{MPa}$, and a Poisson's ratio of 0.3 . According to the characteristics of the surrounding rock, the spacing of surrounding holes and the minimum resistance line of surrounding holes are reasonably selected. The auxiliary holes are staggered and evenly arranged. The bottom of peripheral holes and auxiliary holes are on the same vertical plane, and the excavation footage is $1.0 \mathrm{~m}$. The maximum single shot charge for smooth blasting of tunnel is $20.4 \mathrm{~kg}$. According to the experience, the measured vibration frequency and range are estimated [25], and the test equipment is Topbox vibration recorder.

In the process of on-site monitoring, due to many uncertain factors, some monitoring points are destroyed 


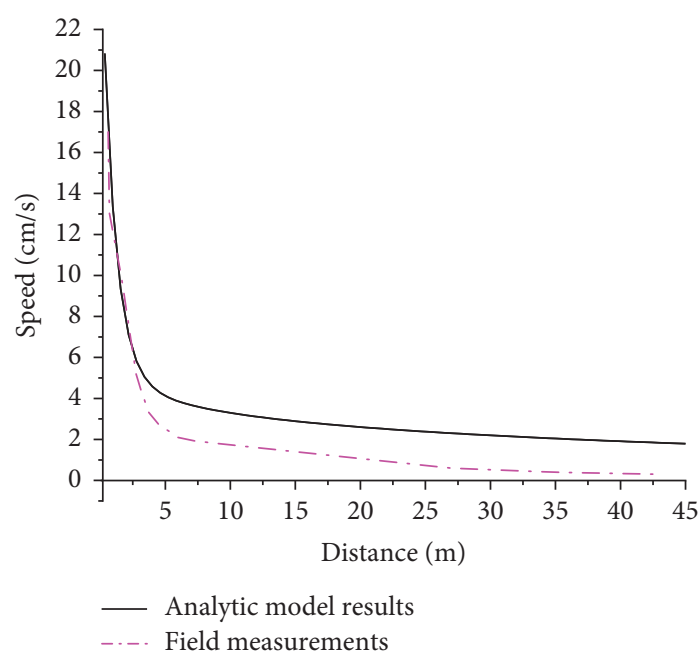

(a)

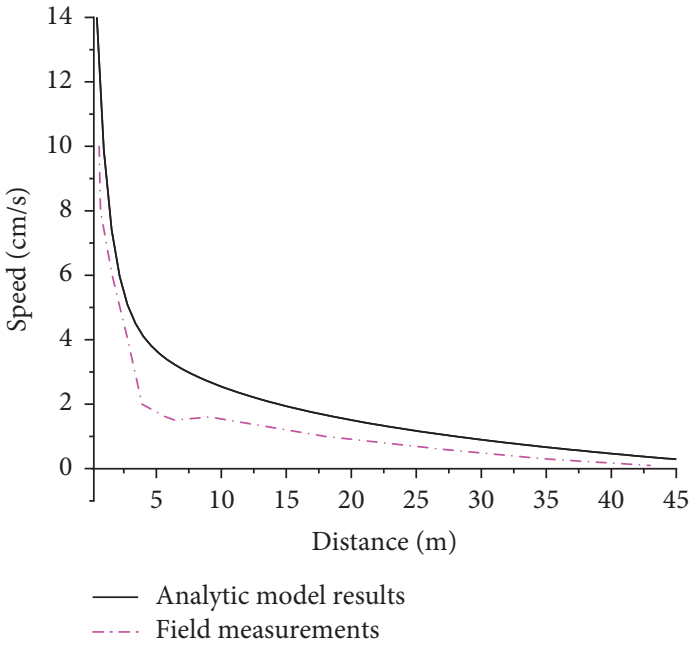

(b)

FIGURE 14: Comparison of analytical results and measured values of vibration velocity. (a) Variation of radial speed with axial distance. (b) Variation of axial speed with axial distance.

during the monitoring process, leading to some abnormal monitoring data, which affects the collection and analysis of monitoring data. Therefore, the abnormal monitoring data are eliminated and optimized, but the effectiveness of the measured data is not affected.

5.2.2. Analytical Solution of Velocity Field. By substituting the relevant parameters into equations (3) and (5), the velocity field caused by short footage blasting load is compared with the field measured value of the Yeshanhe tunnel project, as shown in Figure 14.

The comparison results show that the results of the analytical model of vibration velocity are in poor agreement with the field measured data. In fact, the main reason for the contradiction is that the influence of support structure on the vibration velocity of surrounding rock is not considered in the analytical formula. Due to the large stiffness of the supporting structure, the deformation of the surrounding rock can be obviously restrained and the vibration velocity of the surrounding rock can be effectively reduced. However, they also have something in common: the curve trajectory decreases exponentially with the axial distance, which is consistent with the conclusion in Section 5.1.2.

\section{Conclusions}

(1) Considering the cumulative effect of short footage multiple blasting load, according to the characteristics of displacement potential function of blasting seismic wave, the particle motion equation of the surrounding rock is obtained by the method of separating variables, and the variation law of vibration velocity with axial distance, radial distance, and time is given.
(2) Through the analysis of vibration velocity and displacement change of different sections under grade $\mathrm{V}$ surrounding rock, it can be seen that the damage accumulation effect occurs in the surrounding rock of each section during blasting construction, among which the accumulation at the arch bottom is the largest, and the peak value of vibration velocity and displacement at other measuring points are relatively small, but the damage of surrounding rock is still accumulating gradually.

(3) From the displacement nephogram of the concrete spraying layer, the displacement of the concrete spraying layer is accumulated after three times of blasting. The results show that the cumulative damage of the shotcrete layer under short footage multiple blasting loads affects the stability of the supporting structure.

(4) The results of the dynamic response analysis model are in good agreement with those of numerical simulation. Both of them show that the cumulative damage of the surrounding rock caused by short footage blasting load increases with the increase of blasting times. Moreover, the attenuation of radial velocity in the axial distance is more severe, and the support structure within $0.5 \mathrm{~m}$ from the working face is in danger of being damaged by blasting vibration.

\section{Data Availability}

The data used to support the findings of this study are available from the corresponding author upon request.

\section{Conflicts of Interest}

The authors declare that they have no conflicts of interest. 


\section{Acknowledgments}

The authors would like to express their gratitude to the Ministry of Education of Humanities and Social Science Foundation of China (no. 20YJAZH022).

\section{References}

[1] S. Kumar, A. K. Mishra, B. S. Choudhary, R. K. Sinha, D. Deepak, and H. Agrawal, "Prediction of ground vibration induced due to single hole blast using explicit dynamics," Mining, Metallurgy \& Exploration, vol. 37, no. 2, pp. 733-741, 2020.

[2] L. Ahmed and A. Ansell, "Structural dynamic and stress wave models for the analysis of shotcrete on rock exposed to blasting," Engineering Structures, vol. 35, no. 1, pp. 11-17, 2012.

[3] W. H. Zhou, Z. B. Li, X. Wu et al., "A novel method to evaluate the effect of slope blasting under impact loading," Shock and Vibration, vol. 2020, Article ID 6029190, 17 pages, 2020.

[4] G. Paneiro, F. O. Durão, M. C. e. Silva, and P. A. Bernardo, "Neural network approach based on a bilevel optimization for the prediction of underground blast-induced ground vibration amplitudes," Neural Computing and Applications, vol. 32, no. 10, pp. 5975-5987, 2020.

[5] C. Dai, Y. Long, Y. Lv, W. Hou, and H. Sui, "Water inrush mechanism and safety control in drilling and blasting construction of subsea tunnel," Journal of Coastal Research, vol. 94, no. sp1, pp. 218-222, 2019.

[6] J.-H. Shin, H.-G. Moon, and S.-E. Chae, "Effect of blast-induced vibration on existing tunnels in soft rocks," Tunnelling and Underground Space Technology, vol. 26, no. 1, pp. 51-61, 2011.

[7] N. Jiang and C. Zhou, "Blasting vibration safety criterion for a tunnel liner structure," Tunnelling and Underground Space Technology, vol. 32, pp. 52-57, 2012.

[8] N. Yugo and W. Shin, "Analysis of blasting damage in adjacent mining excavations," Journal of Rock Mechanics and Geotechnical Engineering, vol. 7, no. 3, pp. 282-290, 2015.

[9] D. Saiang, "Stability analysis of the blast-induced damage zone by continuum and coupled continuum-discontinuum methods," Engineering Geology, vol. 116, no. 1-2, pp. 1-11, 2010.

[10] A. M. Benselama, M. J.-P. William-Louis, F. Monnoyer, and C. Proust, "A numerical study of the evolution of the blast wave shape in tunnels," Journal of Hazardous Materials, vol. 181, no. 1-3, pp. 609-616, 2010.

[11] R. Tiwari, T. Chakraborty, and V. Matsagar, "Dynamic analysis of a twin tunnel in soil subjected to internal blast loading," Indian Geotechnical Journal, vol. 46, no. 4, pp. 369-380, 2016.

[12] Q. Gao, W. Lu, Z. D. Leng, Z. Yang, Y. Zhang, and H. Hu, "Effect of initiation location within blasthole on blast vibration field and its mechanism," Shock and Vibration, vol. 2019, Article ID 5386014, 18 pages, 2019.

[13] J. H. Chen, J. S. Zhang, and X. P. Li, "Model of rock blastinginduced damage considering integrity of rock mass and its application," Chinese Journal of Geotechnical Engineering, vol. 38 , no. 5, pp. 857-866, 2016.

[14] F. J. Xie, J. S. Zhang, and J. H. Chen, "Blasting-induced fracture zone in rock mass considering integrity of rock mass," Journal of Central South University (Science and Technology), vol. 50, no. 6, pp. 1403-1410, 2019.
[15] F. J. Xie, J. S. Zhang, and J. H. Chen, "Dynamic damage model of rock under impact loads of compression and tension," Journal of Central South University (Science and Technology), vol. 50, no. 2, pp. 420-427, 2019.

[16] X. P. Li, J. L. Lv, Y. Luo et al., "Mechanism study on elevation effect of blast wave propagation in high side wall of deep underground powerhouse," Shock and Vibration, vol. 2018, Article ID 4951948, 15 pages, 2018.

[17] S. Otto, P. Till, and K. Hartmut, "Development of damage and permeability in deforming rock salt," Engineering Geology, vol. 61 , no. $2-3$, pp. 163-180, 2001.

[18] I. L. Meglis, T. Chow, C. D. Martin, and R. P. Young, "Assessing in situ microcrack damage using ultrasonic velocity tomography," International Journal of Rock Mechanics and Mining Sciences, vol. 42, no. 1, pp. 25-34, 2005.

[19] Z. L. Xu, Elastic Mechanics, Higher Education Press, Beijing, China, 2006.

[20] M. W. Lu and X. F. Luo, Theoretical Basis of Elasticity, Higher Education Press, Beijing, China, 1990.

[21] Z. H. Zhao, W. Sun, M. Z. Zhang, X. Gao, and S. Chen, "Fracture mechanical behavior of cracked cantilever roof with large cutting height mining," Shock and Vibration, vol. 2020, Article ID 1641382, 10 pages, 2020.

[22] Z. H. Zhao, M. Z. Zhang, Q. Ma, and B. Chen, "Deviation effect of coaxiality on the rock Brazilian split," Advances in Mathematical Physics, vol. 2020, Article ID 5782457, 8 pages, 2020.

[23] S. S. Xiao, H. S. Wang, and G. W. Dong, "A preliminary study on the design method for large-diameter deep-hole presplit blasting and its vibration-isolation effect," Shock and Vibration, vol. 2019, Article ID 2038578, 11 pages, 2019.

[24] J. H. Yang, W. B. Lu, Y. G. Hu et al., "Accumulated damage in surrounding rocks due to repeated blasting loads during blasting excavation of tunnels," Rock and Soil Mechanics, vol. 35, no. 2, pp. 511-518, 2014.

[25] Z. G. Zhao, J. H. Yang, W. B. Lu et al., "Selection of spraying time for permanent shotcrete in deep-buried tunnels based on evaluation of the influence of blasting vibration," Journal of Vibration and Shock, vol. 34, no. 7, pp. 8-14, 2015.

[26] H. B. Chu, X. L. Yang, S. J. Li, and W. Liang, "Experimental investigation of the propagation and attenuation rule of blasting vibration wave parameters based on the damage accumulation effect," Shock and Vibration, vol. 2018, Article ID 2493149, 9 pages, 2018.

[27] Z. R. Li, "Study on stability of tunnel surrounding rock and bolt-shotcrete support structure under cyclic blasting load," Ph.D. thesis, Shandong Jianzhu University, Jinan, China, 2019.

[28] C. Q. Dai, Y. X. Long, Z. J. Shi, X. Guangxue, and H. Wenzeng, "Development and engineering application of strong permeability grouting material for weathered granite formation," Revista Romana de Materiale-Romanian Journal of Materials, vol. 49, no. 3, pp. 379-387, 2019. 